\section{Case Reports in Ophthalmology}

Case Rep Ophthalmol 2020;11:385-390

DOI: 10.1159/000509157

Published online: July 28, 2020
(C) 2020 The Author(s)

Published by S. Karger AG, Basel www.karger.com/cop

\title{
Nonperfused Peripheral Retinal Area in Eyes with Chronic Rhegmatogenous Retinal Detachment
}

\author{
Tomoaki Tatsumi Takayuki Baba Hirotaka Yokouchi \\ Shuichi Yamamoto \\ Department of Ophthalmology and Visual Science, Chiba University Graduate School of \\ Medicine, Chiba, Japan
}

\section{Keywords}

Rhegmatogenous retinal detachment - Chronic detachment - Retinal nonperfusion .

Fluorescein angiography · Scleral buckling

\begin{abstract}
We report two cases of chronic rhegmatogenous retinal detachment with a nonperfused peripheral retinal area. Case 1 was an 84-year-old woman who presented with a bullous retinal detachment of the inferior retina and a best-corrected visual acuity of 20/500. A small horseshoe tear was detected in the peripheral superior retina. Fluorescein angiography showed a wide area of nonperfused retina in the inferior retina. The retina was successfully reattached by scleral buckling surgery. Case 2 was a 40 -year-old woman who presented with a shallow retinal detachment involving the macula. There were multiple retinal breaks at the pars plana that were secondary to blunt trauma. Fluorescein angiography revealed a wide area of nonperfused retina in the inferior peripheral retina. She underwent scleral buckling surgery, and the retina was successfully reattached. Our findings indicate that clinicians should examine the peripheral retina carefully especially with fluorescein angiography to search for nonperfused areas in eyes with chronic rhegmatogenous retinal detachment.
\end{abstract}




\section{Case Reports in Ophthalmology}

Tatsumi et al.: Nonperfused Retina in Chronic RRD

\section{Introduction}

A rhegmatogenous retinal detachment (RRD) is a vision-threating disorder caused by retinal traction and retinal breaks. The separation of the sensory retina from the retinal pigment epithelium leads to the impairment of retinal metabolism and reduction of visual function. Most cases present with acute reduction of vision, but some detachment cases develop slowly. The incidence of such chronic RRDs is estimated to be about 4.5-29\% of all RRD cases, and they are occasionally found accidentally $[1,2]$.

The characteristics of chronic RRD are: small retinal breaks, breaks located in the inferior retina, absence of posterior vitreous separation, and young age [2]. Because the symptoms of chronic RRD are usually mild and hardly noticed, chronic RRD cases are often found by chance, and the delay in the diagnosis results in poor visual outcomes even after the successful reattachment surgery. On the other hand, chronic RRD cases are occasionally misdiagnosed as nonrhegmatogenous retinal detachment, uveitis, and degenerative retinoschisis [3].

We report two cases of chronic RRD that were found to have a nonperfused peripheral retina. Peripheral retinal ischemia is not common in eyes with RRD except for the RRD that occurs in eyes with peripheral vascular disorders such as familial exudative vitreoretinopathy (FEVR) [4], retinopathy of prematurity (ROP) [5], and sickle cell retinopathy [6].

\section{Case Presentation}

\section{Case 1}

An 84-year-old Japanese woman reported that the vision in her left eye had been blurred for about 1 month. She stated that she had undergone bilateral cataract surgery 4 years earlier, and her medical history showed that she had diabetes, autoimmune hepatitis, and chronic renal failure. She was being treated by insulin for the diabetes and $10 \mathrm{mg}$ of oral prednisolone daily for the hepatitis.

Our initial examination detected a left retinal detachment accompanied by a subretinal band, and the proliferative vitreoretinopathy (PVR) was grade C type 3. Her best-corrected visual acuity was 20/22 in her right eye and 20/500 in her left eye. Her refractive error (spherical equivalent) was $-2.5 \mathrm{dpt}$ in her right eye and $-0.5 \mathrm{dpt}$ in her left eye. The intraocular pressure was $11 \mathrm{~mm} \mathrm{Hg}$ in her right eye and $3 \mathrm{~mm} \mathrm{Hg}$ in her left eye. Her anterior segment was normal with a stable intraocular lens. There were no obvious retinal breaks observed ophthalmoscopically and few pigment clumps were detected in the vitreous. An exudative retinal detachment was suspected (Fig. 1a). An area of nonperfusion was observed at the inferior peripheral retina by fluorescein angiography (FA; Fig. 1b). Although screening tests including laboratory tests and chest X-ray were negative for uveitis and infection, we first treated this case as uveitis. The detachment did not respond to a sub-Tenon's capsule injection of $20 \mathrm{mg}$ of triamcinolone acetonide. A careful fundus examination with scleral depression revealed a small retinal tear at $12 o^{\prime}$ clock of the peripheral retina. The retina was successfully reattached by scleral buckling surgery (Fig. 1c), and her visual acuity had improved to 20/150 at 3 months after the surgery. FA showed that the former area of nonperfusion was not apparent because of the atrophy of the pigment epithelium (Fig. 1d).

Case 2

A 40-year-old Japanese woman was referred to the Chiba University hospital to treat a retinal detachment in her left eye. She was aware of a defect of her vision in the inferior field 


\section{Case Reports in Ophthalmology}

Case Rep Ophthalmol 2020;11:385-390 DOI: 10.1159/000509157

c) 2020 The Author(s). Published by S. Karger AG, Basel www.karger.com/cop

Tatsumi et al.: Nonperfused Retina in Chronic RRD

of her left eye and stated that she began noting it 2 months earlier. She had no ocular and systemic medical history except for a blunt trauma on her left eye 15 years earlier. Her visual acuity was 20/18 in her right eye with a refractive error (spherical equivalent) of $-6.0 \mathrm{dpt}$ and $20 / 20$ in her left eye with a refractive error of $-8.5 \mathrm{dpt}$. The intraocular pressure was $12 \mathrm{~mm}$ $\mathrm{Hg}$ in her right eye and $7 \mathrm{~mm} \mathrm{Hg}$ in her left eye.

At the initial examination, an inferior retinal detachment with subretinal strands was observed, and the PVR was grade C type 3 (Fig. 2a). Because a retinal break was not found and the pigment clumps were sparse in the vitreous, she was diagnosed with an exudative retinal detachment. However, FA showed a nonperfused area in the inferior peripheral fundus without leakage from the retinal vessels (Fig. 2b). Although screening tests including laboratory tests and chest X-ray were negative for uveitis and infection, we first treated this case as uveitis. She was treated by oral prednisolone and intravitreal bevacizumab which might be effective for exudation from undetected source of leakage such as choroidal neovascularization. However, the detachment did not decrease. Careful fundus examination revealed multiple small breaks at the superonasal pars plana. She underwent scleral buckling surgery, and the retina was successfully reattached (Fig. 2c). The retinal nonperfused area remained nonperfused with mild leakage of the dye (Fig. 2d).

\section{Discussion and Conclusion}

A chronic RRD is an uncommon type of RRD. Our cases were initially diagnosed with exudative retinal detachment and treated with steroids. However, the retinal detachment was not affected by the anti-inflammatory therapy, and small retinal breaks were found by careful examination of the peripheral retina with scleral depression. Our cases did not have any peripheral vascular abnormalities as is found in eyes with FEVR and ROP. We suggest that the long-standing retinal detachment lead to peripheral retinal ischemia and the development of nonperfused retinal areas. Usually, FA is not performed in cases with RRD even if it is chronic. Therefore, peripheral retinal nonperfusion may be missed in many chronic RRD cases.

Chronic RRD cases have been reported in eyes with peripheral sea fan retinal neovascularization [7]. Although our two cases of chronic RRD had nonperfused retinal areas, they did not develop retinal neovascularization. We suggest that the level of ischemia-inducing growth factors, such as vascular endothelial growth factor (VEGF), released was not high in the nonperfused areas. The reason for the lower VEGF level may be because the demand for oxygen by the peripheral retina is not high as is observed in highly myopic eyes [8]. In highly myopic eyes, the retinal neovascularization is absent despite of wide nonperfusion of the retina. The VEGF level seems not elevated in myopic eyes because the oxygen demand is low because of dehiscence and degeneration of the retina.

Chen et al. [9] have reported the peripheral vascular pattern in eyes with RRD by fluorescein angiography. They found that peripheral vascular anomalies are common in cases with RRD. The curving route of peripheral vasculature was most common (54.8\%) but some cases showed peripheral nonperfusion. The retinal breaks were located in the peripheral nonperfused areas in their series but our cases showed no association between the location of retinal break and nonperfusion. The inferior nonperfusion in our cases suggested that the ischemic change was a result of the chronic detachment and was not a cause of retinal break. The relationship between vascular change and retinal break in RRD is probably not uniform and further investigations are needed. 


\section{Case Reports in Ophthalmology}

Tatsumi et al.: Nonperfused Retina in Chronic RRD

A reperfusion of the earlier nonperfused retinal area was detected by FA, but the development of capillaries was not clearly observed. Degenerated retinal pigment epithelium makes detailed observation of peripheral retina difficult. A more detailed examination of the peripheral retina by ultra-widefield FA is necessary.

In conclusion, the presence of a nonperfused area of the peripheral inferior retina was observed in two cases of chronic RRD. RRDs are generally not associated with peripheral vascular abnormalities such as FEVR and ROP. The chronic development of retinal detachment may play a role in the formation of nonperfused peripheral retina.

\section{Acknowledgement}

The authors thank Professor Emeritus Duco Hamasaki of the Bascom Palmer Eye Institute, University of Miami, FL, USA, for providing critical discussions and suggestions to our study and editing the final manuscript.

\section{Statement of Ethics}

The patients consented to the publication of the case in writing.

\section{Conflict of Interest Statement}

The following authors have no financial disclosures: T.T., H.Y.

T.B.: personal fees from Bayer, personal fees from Kowa, personal fees from Santen, personal fees from Senju, personal fees from Alcon, grants and personal fees from Novartis, outside the submitted work.

S.Y.: grants and personal fees from HOYA, grants and personal fees from Senju, grants and personal fees from Pfizer, grants and personal fees from Santen, grants and personal fees from Alcon Japan, grants and personal fees from Alcon Pharma, grants and personal fees from Bayer, grants and personal fees from Kowa, personal fees from Nikon, personal fees from Wakamoto, personal fees from Chuo Sangyo, personal fees from Daiichi Sankyo, personal fees from Jamex, personal fees from Sun Contact Lens, personal fees from Finedex, personal fees from Novartis, personal fees from Chugai, personal fees from Abbvie, outside the submitted work.

\section{Funding Sources}

This research was not supported by any competing interests of grants.

\section{Author Contributions}

Conception and design: T. Baba.

Data collection: T. Tatsumi, H. Yokouchi.

Analysis and interpretation: T. Baba, S. Yamamoto.

Overall responsibility: T. Baba, T. Tatsumi, H. Yokouchi, S. Yamamoto. 


\section{Case Reports in Ophthalmology}

\begin{tabular}{l|l}
\hline Case Rep Ophthalmol 2020;11:385-390 \\
\hline DOI: 10.1159/000509157 & $\begin{array}{l}\text { @ 2020 The Author(s). Published by S. Karger AG, Basel } \\
\text { www.karger.com/cop }\end{array}$ \\
\hline
\end{tabular}

Tatsumi et al.: Nonperfused Retina in Chronic RRD

\section{References}

1 Brod RD, Flynn HW Jr. Asymptomatic rhegmatogenous retinal detachment. Curr Opin Ophthalmol. 1996 Jun;7(3):1-6.

2 Li YM, Fang W, Jin XH, Li JK, Zhai J, Feng LG. Risk factors related to chronic rhegmatogenous retinal detachment. Int J Ophthalmol. 2012;5:92-6.

3 Jeroudi AM, Shah V, Blinder KJ, Shah GK. Management of Degenerative Retinoschisis-Associated Retinal Detachment. Ophthalmol Retina. 2017 Jul - Aug;1(4):266-71.

4 Benson WE. Familial exudative vitreoretinopathy. Trans Am Ophthalmol Soc. 1995;93:473-521.

5 Yokoi T, Hiraoka M, Miyamoto M, Yokoi T, Kobayashi Y, Nishina S, et al. Vascular abnormalities in aggressive posterior retinopathy of prematurity detected by fluorescein angiography. Ophthalmology. 2009 Jul;116(7):1377-82.

6 Han IC, Zhang AY, Liu TY, Linz MO, Scott AW. UTILITY OF ULTRA-WIDEFIELD RETINAL IMAGING FOR THE STAGING AND MANAGEMENT OF SICKLE CELL RETINOPATHY. Retina. 2019 May;39(5):836-43.

7 Georgalas I, Paraskevopoulos T, Symmeonidis C, Petrou P, Koutsandrea C. Peripheral sea-fan retinal neovascularization as a manifestation of chronic rhegmatogenous retinal detachment and surgical management. BMC Ophthalmol. 2014 Sep;14(1):112.

8 Kaneko Y, Moriyama M, Hirahara S, Ogura Y, Ohno-Matsui K. Areas of nonperfusion in peripheral retina of eyes with pathologic myopia detected by ultra-widefield fluorescein angiography. Invest Ophthalmol Vis Sci. 2014 Mar;55(3):1432-9.

9 Chen SN, Hwang JF, Wu WC. Peripheral Retinal Vascular Patterns in Patients with Rhegmatogenous Retinal Detachment in Taiwan. PLoS One. 2016 Feb;11(2):e0149176.
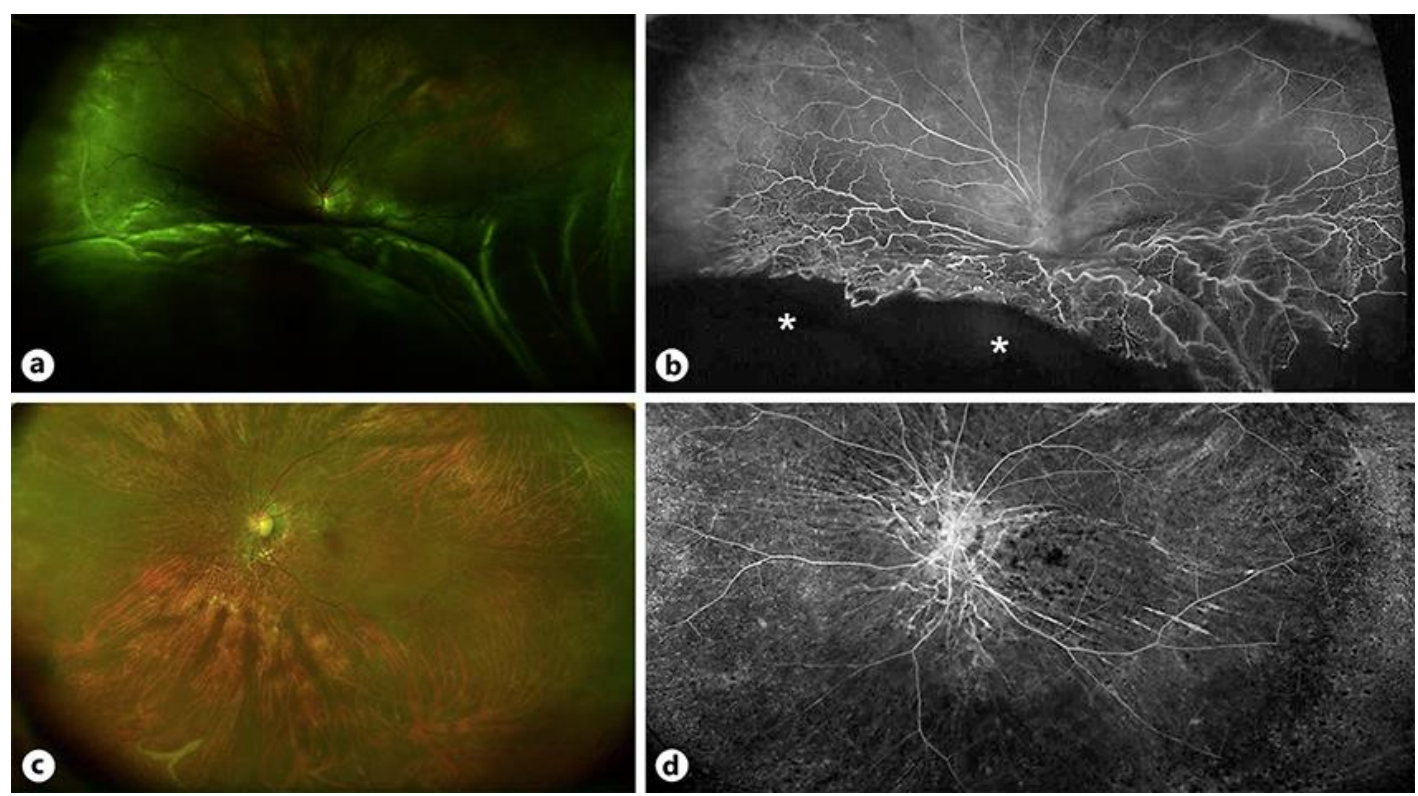

Fig. 1. Ultra-widefield fundus photograph and fluorescein angiogram of case 1. a Preoperative fundus photograph of the left eye of an 84-year-old Japanese woman. An inferior bullous retinal detachment can be seen. b Fluorescein angiogram showing peripheral nonperfused retina at the inferior area (asterisk). No leakage from the retinal vessels can be seen. $\mathbf{c}$ The retina was attached after scleral buckling surgery. $\mathbf{d}$ The retinal nonperfused area is not clearly seen because of the atrophy of the pigment epithelium. 
Case Reports in Ophthalmology
Case Rep Ophthalmol 2020;11:385-390 DOI: $10.1159 / 000509157$

(c) 2020 The Author(s). Published by S. Karger AG, Basel www.karger.com/cop
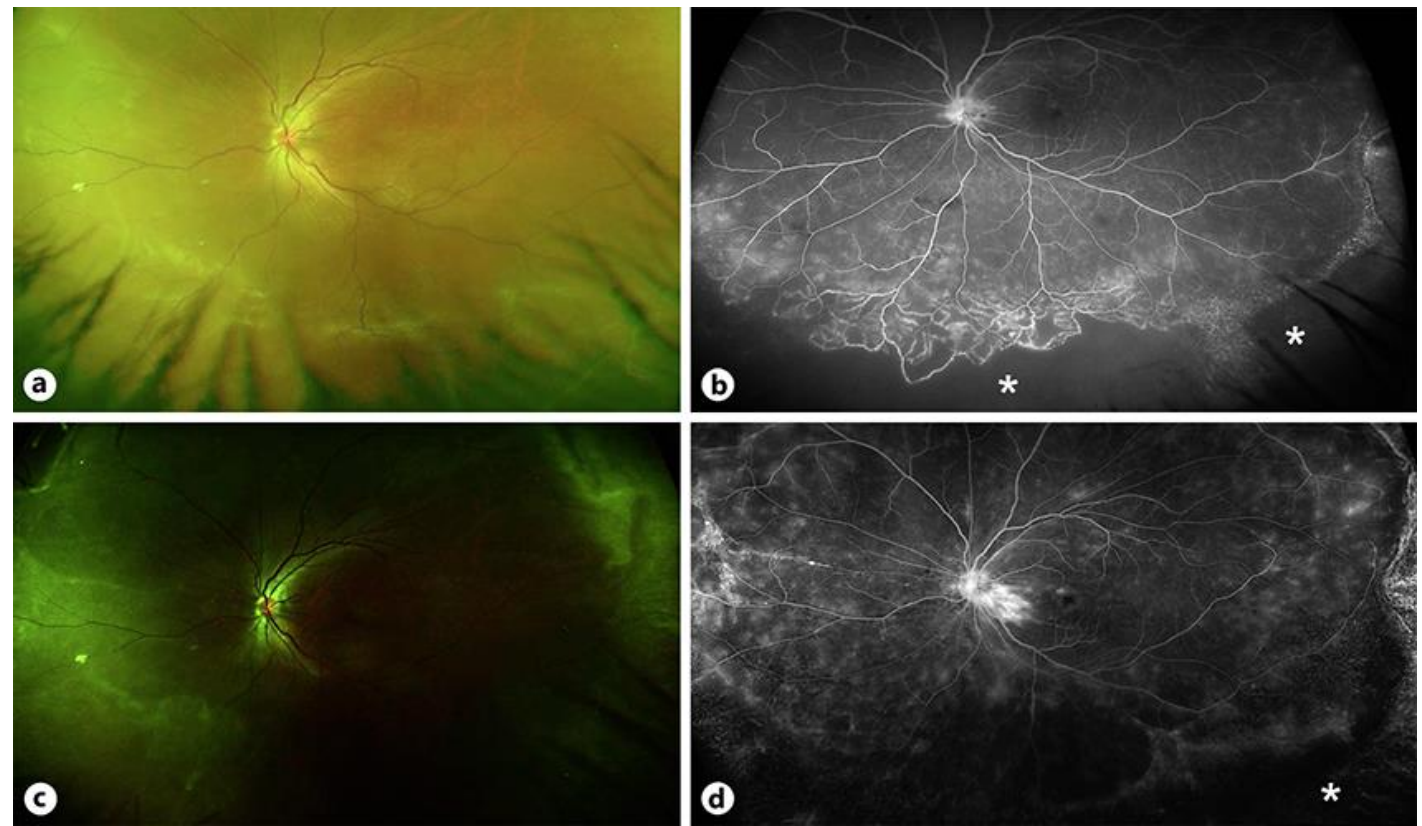

Fig. 2. Ultra-widefield fundus photograph and fluorescein angiogram of case 2. a Preoperative retinal photograph of the left eye of a 40-year-old Japanese woman. Shallow retinal detachments can be seen in the four quadrants. b Fluorescein angiogram shows peripheral nonperfused retina in the inferior area (asterisk). Faint leakage from retinal vessels can be seen. c The retina was attached after the scleral buckling surgery. $\mathbf{d}$ The retinal nonperfused area remains nonperfused with mild leakage of the dye (asterisk). 